\title{
Students' perception on objective structured clinical examination
}

\author{
Bindu Mohandas ${ }^{1, *}$ R Ratheesh ${ }^{2}$ \\ Assistant Professor, ${ }^{1}$ Dept.of Community Medicine, ${ }^{2}$ Dept. of Pharmacology, KMCT Medical College, Calicut, Kerala, India
}

*Corresponding Author:

Email: bindumohandas86@gmail.com

\begin{abstract}
Introduction: Objective Structured Clinical Examination (OSCE) is a reliable and an established and effective multi station test for the assessment of practical skills in an objective and a transparent manner. Though it is a widely accepted new method of clinical evaluation in MBBS, students' view on OSCE is an unhandled area. This study tries to explore students' opinion on OSCE and as well as it rate of acceptance in MBBS Students.

Materials and Method: A semi structured questionnaire was administered to final year MBBS part II students. The data was entered in MS Excel and analysed using SPSS version 16. Results are expressed as proportions.

Results: The mean age of students was $22.58 \pm 0.79$ SD. $58.8 \%$ of the students felt OSCE is an easier method of examination comparing to the traditional clinical examination. They expressed it as an exam that assesses all the domains of learning, more knowledge assessed in short span of time, questions are framed to the point, and it evaluates all areas of the subject. $64.7 \%$ rated OSCE as an easy exam compared to the conventional examination. 52.9\% of the students agreed that OSCE helps to identify their weak areas in clinical skills. $64.7 \%$ agreed that OSCE is a good method to identify their weak areas in practical skills. All students said that instructions given prior to the OSCE exam are very useful. It gives clarity and overall idea about the different stations.
\end{abstract}

Conclusion: Majority of students found OSCE as an easy exam. It helps to identify their weak areas in clinical and practical skills.

Keywords: OSCE, Clinical skill, Practicals.

\section{Introduction}

There has been a growing concern among medical educators about the quality of medical graduates trained in various medical colleges in our country. Data based on the faculty and student perceptions of undergraduate curriculum indicate a need for laying more stress on practical skills during their training and assessment. The Objective Structured Clinical Examination (OSCE) is a reliable and an established and effective multi station test for the assessment of practical skills in an objective and a transparent manner. ${ }^{1}$ It allows for the actual demonstration of applied knowledge and skills rather than testing knowledge alone. ${ }^{2-4}$

OSCE is being regarded as a useful method for assessing the competence skills as well as for enhancing the knowledge required for clinical work. It is an assessment technique in which student demonstrates their competence under a variety of simulated conditions. The OSCE is now being regarded as one of the most valid, reliable, and effective examination for assessment of clinical skill. ${ }^{2}$ The opportunity for formative as well as summative feedback makes OSCE an excellent teaching tool as well. It provides an opportunity to test their attitude and communication skills as well. The clinical competence to be tested is broken down into specific skills, each of which can be tested at a time..$^{1,5,6}$

OSCE is a modern type of examination often used in health sciences (e.g. Midwifery, orthoptics, optometry, medicine, naturopathic medicine, physician assistants/associates, physical therapy, radiography, nursing, pharmacy, dentistry, chiropractic medicine, paramedicine, podiatry, veterinary medicine). It is designed to test clinical skill performance and competence in skills such as communication, clinical examination, medical procedures / prescription, exercise prescription, joint mobilisation/manipulation techniques, radiographic positioning, radiographic image evaluation and interpretation of results. ${ }^{6}$

The current assessment has disadvantages in assessing individual skills and creativity among medical students. Most of the time, the examiners fail to assess the objective role by a student. These methods have been interpreted in many journals and focus has been only on the base of the 'Miller's pyramid of competence'. There has been greater difficulty to evaluate the top levels of the pyramid of competency in a valid and reliable manner. To astound these inadequacies, introduction of OSCE is necessary which will incorporate assessment of clinical skills and competencies necessary for advancement in the medical education. Domains of competencies incorporated in each station in an OSCE will be diverse; overall all domains of competencies are tested. The examination is structured to observe all students on matching content by the same examiners using predetermined guidelines; and a systematic feedback is obtained from both students and the assessors, which can be integrated to enhance the learning through feedback and reflection. OSCE is meant to test the 'shows how' level of the Miller's pyramid. Medical schools across the world have increasingly implemented OSCE and it has now 
been widely described in the medical literature and adopted by the medical and nursing profession. ${ }^{3}$

OSCE is a part of MBBS and postgraduate courses in India. OSCE is an assessment method established and introduced by Hardin in the year 1979, it has been practiced in medical and paramedical courses worldwide. ${ }^{3,7,8}$

OSCE is a recognized, consistent, and active assessment to valuate professional skills in an impartial and an obvious method. ${ }^{7,8}$ Though it is a widely accepted new method of clinical evaluation in MBBS, students' view on OSCE is an unhandled area. This study is an attempt to explore students' opinion on OSCE.

\section{Materials and Method}

The study was done in MBBS students of KMCT Medical College, Calicut after obtaining permission from Institutional Research Committee. During the study period from 3.8 .15 to 14.8 .15 , the semi structured questionnaire was administered in students of final year MBBS part II. Participants for the study were recruited from Medicine department because at present in clinical subjects only OSCE was done according to university guidelines. From 2016 onwards it is incorporated in non clinical subjects also. A total of 20 students were there posted in medicine department during the study period. Only 17 were present for the examination and they were selected for the study. The questionnaire was given after their end posting examination. Examination comprised of a series of stations through which all candidates rotate on a timed basis. In each station, the candidate is faced with a simulated task or problem; the candidate is required to perform specific functions to complete the task or address the problem like demonstration of a specific clinical examination skill, completion of a short written assessment or interpreting clinical or laboratory test results. . The data was entered in MS Excel and analysed using SPSS version 16. Results are expressed as proportions.

\section{Results}

Out of the 20 selected final MBBS part II students, $29 \%$ were males and $71 \%$ were females. The mean age of students was $22.58 \pm 0.79$ SD. $58.8 \%$ of the students felt OSCE is an easier method of examination comparing to the traditional clinical examination. But only $47.1 \%$ agreed to the fact of accepting it as a well structured examination. They expressed it as an exam that assesses all the domains of learning, more knowledge assessed in short span of time, questions are framed to the point, and it evaluates all areas of the subject.

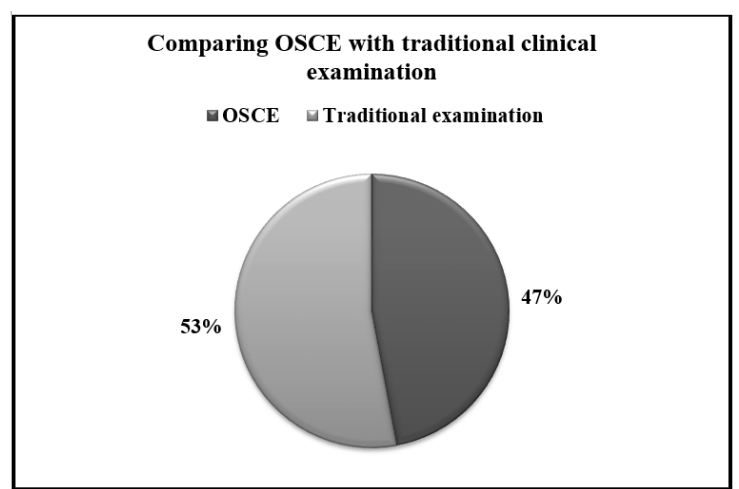

Fig. 1: Comparison of OSCE with traditional clinical examination

$52.9 \%$ of the students had a view that in OSCE they are not able to express themselves fully, it also depends on the patient cooperation in manned stations, includes only spot performance, if answers are partially correct in response stations no marks are obtained and, in limited time more things to do which creates tension.

$64.7 \%$ rated OSCE as an easy exam compared to the conventional examination. Some of the explanations given for this were that they have to see only what they are instructed for, and patients with findings are kept in manned stations so that they do not have to search for the things, when the procedure is done correctly full marks are awarded.

$35.3 \%$ of the students were in opinion that OSCE is a difficult exam because of the time limitation and inability to establish rapport with real patients in time.

$52.9 \%$ of the students agreed that OSCE helps to identify their weak areas in clinical skills. $64.7 \%$ agreed that OSCE is a good method to identify their weak areas in practical skills.

$52.9 \%$ of students agreed that OSCE assess all the domains of learning. Only $41.2 \%$ were satisfied with the new method of examination because of the equal importance given to both theory and practical aspects of the subject, easy mark scoring and increase in the observation skill of the student. Some reasons for the dissatisfaction were inadequate time for completion, more of objective nature of the exam, not assessing the weak areas of the student.

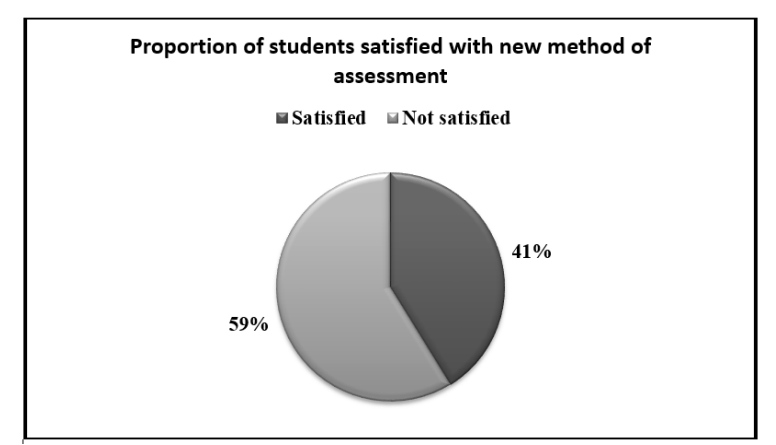

Fig. 2: Students satisfaction with new method of assessment 
$58.8 \%$ of students agreed that OSCE is a stressful examination because of time bound task completion. $41.2 \%$ said that it is not as stressful exam because of the short duration of the exam and more aspects of the subject is assessed in short period of time.

$70.6 \%$ of students said that it is very easy to perform in unmanned station because there is nobody to observe them which indirectly relieve their tension and anxiety, and there is no interruption from the examiner.

$74 \%$ of the students felt some kind of difficulty in their last OSCE exam. The major reasons for the difficulty were inadequate time, stress and inability to remember to the point answer at that time. Majority of them felt that they needed more time to complete the stations.

All students (100\%) unanimously said that instructions given prior to the OSCE exam are very useful. It gives clarity and overall idea about the different stations. It increases the confidence of the student and helps to perform better, and also helps to avoid mistakes.

\section{Discussion}

In our study, $58.8 \%$ of the students felt OSCE is an easier method of examination comparing to the traditional clinical examination. But only $47.1 \%$ agreed to the fact of accepting it as a well structured examination. $64.7 \%$ rated OSCE as an easy exam compared to the conventional examination. $52.9 \%$ of the students agreed that OSCE helps to identify their weak areas in clinical skills. $64.7 \%$ agreed that OSCE is a good method to identify their weak areas in practical skills. These findings of this study were similar with the findings of Siddiqui $\mathrm{FG}^{10}$ in which $70 \%$ of the students felt that OSCE helped them identify areas of weakness in their practical and clinical skills.

$58.8 \%$ of students in our study agreed that OSCE is a stressful examination because of time bound task completion. $70.6 \%$ of students said that it is very easy to perform in unmanned stations. Majority of them felt that they needed more time to complete the stations. These findings of this study were in agreement with the findings of Russell BP. ${ }^{9}$

In our study all students unanimously said that clear instructions given prior to the OSCE exam are very useful, which gives an overall idea about the different stations, and it also increases the confidence of the student and helps to perform better, and also helps to avoid mistakes. This finding of our study was not in agreement with the finding of Siddiqui FG were $50 \%$ of students complained that adequate guidelines were not given prior to the examination. ${ }^{10}$

\section{Conclusion}

Overall $64.7 \%$ of students found OSCE as an easy exam. It helps to identify their weak areas in clinical and practical skills. Only $41.2 \%$ were satisfied with the new method of assessment. As the sample size is small and OSCE is used as an evaluation tool in different semesters, the results cannot be generalized. Further study can be done in future by including students from different semesters.

\section{References}

1. Vivek AS, Amitav AB, Kavita RB. Objective structured clinical examination for undergraduates: Is it a feasible approach to standardized assessment in India. Indian J Ophthalmol. 2011 May-Jun;59(3):211-214.

2. Prabha SC, Chaturvedi SK, Manoj KS. Objective structured clinical examination and its impact on clinical and interpersonal skills: follow up study. Indian $\mathbf{J}$ Psychol Med. 2013 Jul-Sep;35(3):299-301.

3. Kingston R, Sajesh KV. Objective structured clinical examination in Pharm D and clinical pharmacy courses in India; a rising need to acquaint. Indian Journal of Pharmaceutical Education and Research. 2013 OctDec;47(4):1-6.

4. Zubair A, KhooHoon E. Assessment of clinical competence. Basics in medical education. Singapore: World scientific publishing Co.Pte.Ltd;2007, p181-84.

5. Carol C, Robert E. The objective structured clinical examination - a step in the direction of competency based evaluation. Arch Pediatr Adolesc Med. 2000;154(7):736741.

6. https://en.wikipedia.org/wiki/Objective_structured_clinic al_examination

7. James AM, Hollis WM. How to prepare and implement OSCE. The committee on testing and evaluation association for surgical education; 2001, p46-52.

8. David N. Robert C. Assessing the students. A handbook for medical teachers. $4^{\text {th }}$ edition. New York: Kluwer academic publishers; 2002, p151-55.

9. Russell BP, Andrea W, Michelle B, Michael BJ, Celia DCC. Student evaluation of an OSCE in paediatrics at the University of the West Indies, Jamaica. BMC Medical Education. 2004, 4:22

10. Siddiqui FG. Final year MBBS students' perception for observed structured clinical examination. J Coll Physicians Surg Pak. 2013 Jan;23(1):204. 